\title{
Traditional Birth Attendants and Obstetric Risks and Management in Mbiaso Clan, Nsit Ibom Local Government Area, Akwa Ibom State, Nigeria
}

\author{
Dr. Itimitang Wilson Etukudo* \\ Department of Sociology/Anthropology, University of Uyo \\ Ediomo-Ubong E. Nelson \\ Centre for Research and Information on Substance Abuse (Crisa), Uyo, Nigeria
}

\begin{abstract}
This study explores the understanding of obstetric risks and their management among traditional birth attendants (TBAs) in six rural communities in Mbiaso clan of Nsit Ibom Local Government Area of Akwa Ibom State. The communities were selected from a total of 50 which make up the clan through a systematic random sampling technique. A total of 64 TBAs were selected through the use of simple random sampling from the six communities. An in-depth interview technique was used in collecting information from the respondents. Findings from the study underscore that, quite contrary to popular views, TBAs are not unaware of the risks in obstetric care, and they rely on various strategies tonegotiate the risks they face when providing maternity care. The TBAs could be a big asset in decreasing high rate of obstetric complications in the developing countries. To be effective they need to be trained in timely recognition and referrals of mothers at risk, cleanliness and be respected by doctors and nurses.
\end{abstract}

Keywords: Traditional Birth Attendants, obstetric risk, risk management, rural Nigeria.

DOI: $10.7176 / \mathrm{JCSD} / 45-02$

\section{INTRODUCTION}

In many nations, two different medical health systems exist: (1) modern system consisting of scientific medicine, doctors, nurses, clinics and hospitals; and (2) the traditional system consisting of herbalists, traditional birth attendants (TBAs), mystics, massage and herbal cures. The latter professionals are less visible and are often overlooked by government officials. But in many developing nations, the traditional system has higher credibility and is more fully utilized for many health purposes than the modern system [1]. Like in many developing countries in sub-Saharan Africa, many rural areas in Nigeria lack good health care facilities and trained health personnel. Modern maternal and child health care services are often deficient and inappropriate for women's health needs. In the face of these, rural women patronize the services of traditional birth attendants (TBAs) who are present in large in numbers in their communities for their healthcare needs and that of their children $[2,3,4]$ Thus, in these countries, particularly in rural areas, a majority of the births takes place at home, usually assisted by TBAs. Frequent virginal examination with unclean hands and the application of herbal medicines to the vulva or the vagina are some of the practices which may cause obstetric risks. Pelvic sepsis may follow after deliveries or abortions and, when untreated, may lead to chronic pelvic inflammatory disease which is the underlying cause of many cases of infertility, menstrual disorders and ectopic pregnancies [5].

With the emergence of HIV/AIDS, however, public health experts have questioned TBAs' understanding and awareness of the risks inherent in pregnancy and birth delivering and their ability to manage births and prevent the transmission of HIV [6,7]. As a result, public health programmes tend to relegate TBAs to mere appendages of skilled attendants (hospital-based doctors, nurses and midwives), who escort pregnant women to hospitals and provide emotional support to women in labour. Driven by public health experts and bio-medical professionals, these programmes rarely acknowledge or respect the fact that TBAs are sensitive and responsive to the risks in their work, and have evolved tested ways of managing them. In the study of obstetric complications and the role of traditional birth attendants in Nigeria, information on the risk TBAs face in their work and how they negotiate these risks is limited. Arising from above, this study has as its main objectives the identification of the health risks TBAs in the study area come across during obstetric care and how these risks are managed. The study, it is believed, will yield results which have the potentials of enriching programmes on maternal reproductive healthcare in rural Nigeria.

\section{THE STUDY AREA}

This study was carried out in Mbiaso, a large rural clan in Nsit Ibom Local Government Area of Akwa Ibom State, Nigeria. The people in these communities are Ibibios and are mostly subsistence farmers who produce such food crops as cassava, plantain, yam, maize, cocoyam, banana, vegetables, etc. They also rear livestock including goats, sheep, pigs and poultry. They rear these livestock in their residential buildings, which are made 
with such local materials as bamboo sticks, mud and palm fronds. A great majority of the people are Christians. A few persons practice traditional religion. Poverty is very high in these communities, and most of the people live in very precarious conditions. An estimated $71.9 \%$ of the people are poor [8]. They lack access to basic social amenities such as modern healthcare facilities, schools, good roads, electricity and potable water supply and communication services. Sanitation is moderate, and illness burden in the area is quite high.

\section{METHODS AND MATERIALS}

A recent Safe Motherhood Project which confirmed the existence of TBs in the study area informed its selection as the study site. Six rural communities in Mbiaso, namely: Ikot Nya, Afaha Ikot, Afaha Offiong, Edebom, Ikot Obio Etan and Afia Nsit were selected from a total of 50 communities which make up the clan through a systematic random sampling. Approximately 3,900 persons are in each of these communities, going by the 2006 census figures. Local informants were enlisted to help in identifying and listing all TBAs in the selected communities. This list served as the sample frame from which the respondents were selected using a simple random sampling technique. A total of 64 TBAs were selected from the six communities, and the TBAs who run birth homes were surveyed for the study.

An in-depth interview method was used in this study. All the respondents gave verbal consent to be interviewed. Interviews were conducted by four (4) trained Ibibio-speaking field workers recruited from the University of Uyo and College of Education, Afaha Nsit, all in Akwa Ibom State. The research instrument was validated by two research methodologists from the University of Uyo, who were unaware of each other's assessments. They critically examined the instrument to ensure validity and reliability. The respondents were visited at home and interviewed. All women used in the study having been told the importance and the benefits of the research willingly agreed to participate in the research. Their informed consent was obtained Interviews were tape-recorded with the verbal consent of each of the respondents, and were later transcribed into the English Language. Field workers and two English majors from the University of Uyo did the transcription. Transcribed responses were reviewed and discussed with field workers and elaborate notes were written as a result. Experts in sociology, anthropology and health education vetted samples of transcribed responses independently. They wrote memos from the analyses of the themes emerging from the data and compared and contrasted the themes in order to specify their properties and linkages between them. They also made insightful comments that helped shape and establish the themes. Some of the narrative responses are quoted verbatim in this paper to illustrate the respondents' views on key themes.

\section{FINDINGS}

\subsection{PROFILES OF THE RESPONDENTS}

The TBAs were all women within the age range of 46 and 69 years. Their mean was 57 years, and they had an average of 19 years experience in traditional midwifery. Most TBAs were natives of the communities they stayed. Others moved into the communities when they got married to men in the areas. They have a low income. Most of the TBAs were widows. Some of them (19) were married, and a few (7) were separated. They were also petty traders, farmers and seamstresses. Only a few (13) had basic elementary education, the highest level being elementary five; and, they were all Christians.

Generally, they learned their healthcare skill from their mothers, grandmothers or other female relatives. Most assumed their midwifery role on the death or retirement of their mothers, grandmothers or other mentors, although a majority of them feel a supernatural calling to the profession.

\subsection{TBAs SERVICES AND CLIENTS}

All the TBAs surveyed said they were well versed in birth delivering, providing ante-natal and post-natal care, treating and curing reproductive health conditions such as vaginal bleeding, infertility, STDs, menstrual problems, neonatal conditions such as infant fever and teething problems. They also said that they offer traditional and modern forms of family planning services, piercing of female infant ear-lobes and perform circumcision. Also, many of the TBAs reported that people consult them on issues such as child-spacing, painful sexual intercourse, weak erection and low sperm count. Some of them told us that they have very potent traditional cures for various disease conditions. And although majority of the TBAs disclaimed it, a few of them admitted that young girls seeking abortion also patronize them for their services.

A TBA affirmed that:

I assist women in labour, treat STDs, circumcise infants, treat infant illness and Another remarked: even treat problems such as weak erection...I do so many things.

Many women in this village and neighbouring ones come to me when they are about to deliver and I assist them. I also circumcise children, do ear-lobe piercing, cure gonorrhea (akpasak), barrenness and other problems. 


\subsection{ATTITUDES OF THE PEOPLE TOWARD TBAS AND THEIR SERVICES}

They are generally held in high prestige in their communities. They have very high credibility because of their perceived "safety" due to the similarity between the socio-economic status and life style and those of their clients and their perceived "competence" due to their advanced age, high spiritual inclination and special knowledge and skills.

Some TBAs said:

We are highly trusted and patronized by people in our communities because of easy access to our services. The services are affordable, reliable, efficient and we are responsive to the cultural beliefs and values of clients. When they come for our services we don't waste their time and we treat them with care and respect; and also make them to feel at home.

Despite the above positive views about TBAs in the study area, some TBAs reported that some people call them names such as "witches" and "filthy old women". These people believe that TBAs use sorcery to kill pregnant women and "eat" babies, and they would blow events such as the death of a client out of proportion to incite relatives of the deceased to seek redress in courts of law. A TBA said:

Some people call us witches. They say we kill women and infants with our witchcraft. This is not true but they spread it around.

Clients of TBAs also make obstetric care difficult by not paying for services. Most of the TBAs reported that some people come to them and receive treatment or deliver babies but will not pay for such services.

A TBA reported that:

Some of our clients cannot pay for their services, despite the low cost of our services. This is not deliberate; they are very poor. This makes it difficult for TBAs to procure requisite obstetric essentials such as cotton wool, razor blades, towels etc. when they are depleted. As a result, TBAs improvise existing supplies to the detriment of clients.

\subsection{HEALTH RISKS DURING OBSTETRIC CARE AND THEIR MANAGEMENT}

TBAs described birth care problems as undesirable occurrences during birth care, death of a client, disabilities and HIV infection. They maintained that risks are integral part of obstetric care and that managing risks can only reduce them but cannot completely eradicate them. They further noted that both clients and care-givers were at risk. Pre-partum and post-partum care, some TBAs observed, is inherently risky and hazardous. A woman in labour is said to be traveling on the "road destined for all women" (usun afid ibaan). They may or may not return from this journey. The journey is said to be an "uneasy", "painful" and "difficult" one, and the women who go through it need the support of their spouses, relatives and the TBAs. Some TBAs narrated how frightened they were any time they saw a woman go through the agony of labour. They said they empathized deeply with such women. Spouses of the women frantically visit birth homes every now and then. They equally pale in fear when pregnancy becomes difficult. All the TBAs interviewed agreed that obstetric care is essentially risky, and that it takes determination and sense of calling to persevere in the practice. A TBA, for instance, noted:

This work is very difficult, if God is not with one, she could end up in serious trouble.

Safe delivery and the well-being of their clients were frequently mentioned as the most important considerations in traditional midwifery. A TBA told us that:

We go to any length to ensure that our clients were safe and return home in soundness. We fear the death of a client as this may result in serious problem with the client's relatives. Problem will occur when a pregnant woman dies in our homes. The husband and her people will hold us responsible for the death.

TBAs also spoke eloquently about the risk of HIV infection. They observed that it was possible for HIV to be transmitted during obstetric care because there is frequent contact with blood, a major body fluid which carries the virus. They pointed out that since it is not possible to tell who is infected, unless a medical test is carried out,it was necessary for them to guard against HIV infection during obstetric care. A TBA put it thus:

You can pass HIV to your client if you are infected or she could give it to you if she is positive. You know we touch blood always and that is why that can happen.

TBAs manage HIV infection risks in many ways. Those who observe open wounds on their palms would use hand gloves every time they assist birth or provide service. They use a new pair of gloves each time they assist births or provide care to avoid transmitting the infection from a client to another. A TBA said:

I don't assist a woman without wearing a pair of hand gloves, because that is what I was taught in the hospital. Using bare hands is risky because one could get or transmit the virus. 
Some other TBAs pointed out that when they have wounds they don't assist births until the wound heals completely. In the interim, they ask a colleague (another TBA) to help them and they usually appreciate this help with gifts. This help was mutual because when the other TBA also has need and asks for the former's help, she too obliges. A TBA whose clients were assisted by another TBA because she sustained injuries from farming activities, told us:

What we do is, if I have wounds on my palms, I always ask my sister (a fellow

TBA) to help me attend to my clients. When she needs my help, I will also help her.

Others told us that when they recognize signs and symptoms of HIV in a client, such as weight loss, drowsiness, oral thrush and persistent fever, they would encourage the client to go to the hospital where she will be tested and given appropriate medical care. In some cases, they encourage women to go to the hospital, to ensure that they do not turn back. Overall, preventing HIV transmission during obstetric care requires deft, alertness and focus.

\section{Discussion}

Studies $[9,10,2,11,3,12,13,14,15]$ have examined various aspects of traditional midwifery, including the types of services they provide, TBAs' perception of obstetric complications, socioeconomic characteristics of their clients and the reasons why people utilize TBAs.

The present study used qualitative method to investigate TBAs' notions of obstetric risks and how they negotiate these risks. The setting is Mbiaso, a rural clan in Akwa Ibom State, Nigeria. Emerging evidence brings to the limelight some critical insights, which underscores the validity of lay notions and representations of risks. Firstly, TBAs' eloquence and forthrightness in describing the risks they face in obstetric care punctures mainstream public health discourse on traditional midwifery, which portrays it as a potentially dangerous and hazardous practice and depict TBAs as unskilled care-providers who are unaware of the risks inherent in obstetric care and are incapable of managing them $[16,7,6]$. TBAs in the present study display fairly adequate knowledge of the nature and types of obstetric risks and the potential sources of these risks. Their articulation of their experiences in traditional midwifery provides an excellent account based on first-hand experience of the processes that precipitate risks in obstetric care. Their accounts show clear evidence that they understand the risk factors in obstetric care. These include popular attitudes towards and perception of TBAs and poor socioeconomic conditions in rural areas. The behaviour of clients, their spouses and relatives were also implicated as risk factors. So was improvising depleted obstetric supplies, which renders traditional midwifery care inefficient. Evidence also shows that obstetric risks are mediated by local cultural values and economic realities. Thus, as interview accounts unravel, pregnancy and birthing are inherently risky and these risks derive from the social, cultural and livelihood context of women's existence. Obstetric risk affects everyone from TBAs to clients' spouses and relatives. Although spouses and relations of clients are rarely mentioned maternity care-seeking accounts, they are nevertheless an integral part of the process.

It is also observable from the study what obstetric risks consist of. The death of a pregnant woman and HIV infection resulting from contact with blood are the major risks. The death of a woman puts TBAs at risk of persecution from relations of the deceased. Furthermore, the sources of obstetric risks are interwoven and variably interconnected. For instance, poor socioeconomic conditions in local communities undermine local people's ability to pay for the services they obtained from TBAs. The result is that TBAs cannot procure essential obstetric supplies, and this, in turn, cripples the efficiency of their services. However, TBAs' awareness of the implications of lack of basic essentials for the kind of services they provide for their clients' suggests that they are not indifferent to the problems they confront in their work. Their attempt to improvise existing supplies in the face of scarcity and lack of financial resources to procure them derives not from external pressure, but from their personal and collective decision. TBAs constantly search for and evolve new ways of improving service efficiency and managing risks. Their capacity to engage actively with risks offers an entry point for programmes aiming to harness the potentials of traditional midwifery in the quest to improve access to maternal reproductive healthcare for women in poor rural communities.

TBAs adopt different strategies in their attempt to manage risks and this suggests that they are not passive and helpless in the face of hazards. By taking such precautionary measures as treating wounds, using hand gloves when assisting births, TBAs positively grapple with the risk of HIV infection. Similarly, there is evidence that TBAs are aware of the collective nature of their work risks, and they collaborate in addressing them. Thus, those who have wounds on their hands do not assist birth but enlist the help of colleagues. This collaboration in the management of obstetric risk creates a social capital base from which TBAs can draw mutual support and enrich their work. This capital base consists of "inter personal trust, norms of reciprocity and social engagements that foster community and social participation. It is also the actual or potential resources that inherent within social networks or groups for personal benefits. Social capital theorists $[17,18,19]$ recognize the value of this important resource for procuring benefits in the face of scarce resources. Evidence from this study suggests that 
TBAs draw from this resource base to negotiate the risk of HIV infection in obstetric care.

\section{Conclusion}

Existing literature on traditional midwifery portrays the profession as a risky and hazardous one, and the practitioners (TBAs) themselves are vilified and seen as naïve, unskilled and potentially dangerous care-givers who do not grasp the risk inherent in obstetric care, and cannot manage births and prevent HIV infection from being transmitted from one client to the other. Public health programmes often relegate TBAs to the margins of the healthcare delivery system. They are made to serve as appendages of skilled attendants, referring and helping transport pregnant women to hospitals and providing emotional support for women during labour. But the views and notions of TBAs themselves with respect to the risks in their work are rarely privileged. This finding shows that the surveyed TBAs were aware of and actively engage with the risks in obstetric care. TBAs rely on various lay strategies to identify and negotiate the risks they face when providing maternity care. TBAs' assertiveness in the face of risks presents critical scope for interventions aiming to advance their capacity to negotiate work hazards and improve efficiency in their work.

This study investigated lay notions and management of risks among studied TBAs in rural Areas of Akwa Ibom State. Findings from the study underscore that, quite contrary to popular views, TBAs are not unaware of the risks in obstetric care, neither are they passive or panicky in the face of these risks by striving to improve service efficiency, referring cases of complications and those showing symptoms of HIV to hospitals, using hand gloves, collaborating with other TBAs, among others.

A large number of TBAs are present in developing countries in most of the rural areas where no other health care facility exists. And it may take a very long time for these countries to provide qualified doctors or nurses to all parts of their population. So it is important to use the immense potential which lies in the communities themselves for providing basic health care, thus making it possible for such communities to improve their capacity for serving themselves. TBAs constitute a large component of that potential. The TBAs could be asset in decreasing high rate of obstetric complications in the developing countries. To be effective, they need to be trained in timely recognition and referrals of mother at risk, cleanliness and be respected by doctors and nurses. Doctors and nurses must have very good working relationship with TBAs. The opposition from doctors and nurses could be a barrier to implement TBAs' training and referral network.

\section{REFERENCES}

1. Solomon DS. Traditional Midwives and Family Planning in Asia. Studies in Family Planning 1975; 6(5): $126-133$.

2. Itina SM. Characteristic of traditional birth attendants and their beliefs and practices in the Offot Clan, Nigeria. Bulletin of World Health Organization 1997; 75(6): 563-7.

3. Leferber Y and Voorhoever H. Practices and beliefs of traditional birth attendants" Lessons for obstetrics in the North? Tropical Medicine and International Health 1997; 2:1175-1179

4. Naume ZC. Traditional Birth Attendants and Policy Ambivalence in Zimbabwe. Journal of Anthropology 2014, Article ID 750240, 9 pages. Available from: http://dx.doi.org/10.1155/2014/750240.

5. Asghar, R. J. (1999) Obstetric complications and role of Traditional Birth Attendants in developing countries. Journal of College of Physicians and Surgeons 9(1): 55-57.

6. Population Council/MOH, UoN (2003) Traditional birth attendants in maternal health programmes 2003. Kenya: University of Nairobi.

7. Harrison K. Macroeconomic and the African Mother. Journal of the Royal Society of Medicine, 1996; 89, (36) 1-362,

8. Foundation for Economic Research and Training (FERT) Poverty Profile of Akwa Ibom State. 2001 Uyo: FERT.

9. Izugbara $\mathrm{CO}$ and Brown AS. Women, Pregnancy risks, and birthing related complications: conservations with traditional birth attendants (TBAs) in Nigeria. In R. E. Balm (ed.) Trends in midwifery research New York: Nova Science Publishers 2005; pp.167-183.

10. Izugbara CO and Ukwayi JK. An intercept study of persons attending traditional birth homes in rural southeastern Nigeria. Culture, Health and Sexuality, 2004; 6,101-114.

11. Abioye-Kutey EA, Elias SO, Familus AF et al. The Role of Traditional Birth Attendants in Atakumosa, Nigeria. Journal of Royal Society for the promotion of Health 2001; 121(2): 119-24.

12. Obermeye CM Risk uncertainty, and agency: Culture and safe motherhood in Morocco. Medical Anthropology 2000; 19;173-201.

13. Piper C J. Is there a place for traditional midwives in the provision of community health services? Annals of Tropical Medicine and Parasitological 1997; 91, 237-245.

14. Imogie AO. The practice of traditional birth attendants and women's health in Nigeria 2001 Available 
from: http://rnma.regional.org.al 1/papers/2 8 imogie.htm.

15. Okafor CB and Rizzuto RR. Women's and healthcare providers' views of maternal practices and services in rural Nigeria. Studies in Family Planning 1994; 25(6): 353-61.

16. Good CN, Hunter JM, Katz AH et al. The Interface of sub-systems of healthcare in the developing world: Toward Healthcare initiatives in Africa. Social Science and Medicine 1979; 13:141-154.

17. Morrow V. Conceptualizing social capital in relation to the well-being of children and young people: A critical review Sociological Review 1999: 47:744-765.

18. Lomas J. Social capital and health: Implications for public health and epidemiology. Social Science and Medicines. 1998; 47: 1181-1188.

19. Alaszweski A. Risk Communication: Identifying the Importance of Social Context. Health, Risk and Society 2005; 7:101-105. 